\title{
Crescimento e produção da alface sob reposições hídricas e uso de polímero hidroretentor
}

Uanderson Evangelista Alves ${ }^{1}$, Walter Esfrain Pereira ${ }^{1}$, Izaias Romário Soares do Nascimento ${ }^{1}$, João Paulo de Oliveira Santos ${ }^{1}$, Kennedy Santos Gonzaga ${ }^{1}$, Luis Eugênio Lessa Bulhões ${ }^{2}$, Paulo Henrique de Almeida Cartaxo $^{1}$

${ }^{1}$ Universidade Federal da Paraíba - UFPB. ${ }^{2}$ Universidade Federal de Alagoas - UFAL

\section{Resumo}

A alface é uma hortaliça bastante exigente em água, o que pode limitar sua produção em regiões com carência hídrica. Assim, o uso de tecnologias que permitam a maximização do uso da água nessas áreas se faz necessária. Nesse sentido, objetivou-se avaliar o crescimento e produção da alface utilizando diferentes reposições hídricas e polímero hidroretentor. $O$ experimento foi conduzido em casa de vegetação em delineamento em blocos com tratamentos ao acaso, utilizando-se esquema fatorial $4 \times 2+2$, referentes as seguintes lâminas de irrigação (100\%; $80 \% ; 60 \% ; 40 \%$ da capacidade de campo), e dois volumes de polímero hidroretentor ( 50 e $25 \mathrm{~mL}$ por planta), além de duas testemunhas, com quatro repetições. Foram determinadas a altura da planta; diâmetro da cabeça; número de folhas por planta; massa fresca e massa da matéria seca da parte aérea (caule + folhas). Observou-se efeito da lâmina de irrigação sob todas as características analisadas, no entanto, não se registrou efeito significativo das doses de polímero hidroretentor. A alface apresenta maior crescimento e produtividade com a lâmina de água de $100 \%$ da capacidade de campo.

Palavras-chave: Lactuca sativa L.; hidrogel; uso eficiente de água.

\section{Growth and production of lettuce under water replacements and use of hydroabsorbent polymer}

\begin{abstract}
Lettuce is a very demanding vegetable in water, which may limit its production in regions with water shortage. Thus, the use of technologies that maximize the use of water in these areas is necessary. In this sense, the objective was to evaluate the growth and yield of lettuce using different water replacements and hydroretentor polymer. The experiment was carried out in a greenhouse in a randomized block design using a $4 \times 2+2$ factorial scheme, referring to the following irrigation depths $(100 \% ; 80 \% ; 60 \% ; 40 \%$ of field capacity). ), and two volumes of hydroretentor polymer (50 and $25 \mathrm{~mL}$ per plant), plus two controls, with four replications. Plant height was determined; head diameter; number of leaves per plant; fresh mass and dry matter mass of shoot (stem + leaves). Irrigation depth effect was observed under all the characteristics analyzed, however, there was no significant effect of hydroretentor polymer doses. Lettuce has higher growth and productivity with the water depth of $100 \%$ of field capacity.

Keywords: Lactuca sativa L.; hydrogel; efficient use of water.
\end{abstract}

1.

\section{Introdução}

O aumento crescente das populações humanas leva a necessidade cada vez maior de produção de alimentos. Cenário esse que se reflete na expansão das áreas destinadas a agricultura, carecendo assim do desenvolvimento de tecnologias destinadas a maximização dos resultados produtivos e a manutenção da qualidade dessas áreas; dentre essas tecnologias, destaca-se a utilização de polímeros hidroretentores (MILANI et al., 2017). 
Esses polímeros são facilmente processados e quimicamente modificados, apresentando propriedades físicas e mecânicas desejáveis para a aplicação em atividades agrícolas; entre os polímeros mais promissores, o uso de uma classe especial tem crescido nas últimas décadas: os hidrogéis (GUILHERME et al., 2015). Esses materiais são incolores, inodoros, não geram poluição no solo e nas águas superficiais, além de não causar fitotoxidez as plantas (TAHERI et al., 2017a).

Os hidrogéis, ao serem adicionados ao solo antes da prática da irrigação, maximizam a utilização da água aplicada. Isso se deve às propriedades desses materiais em absorverem grandes quantidades de água e posteriormente fazerem a liberação gradual desse líquido através de um mecanismo difusor que age concomitantemente com a redução da umidade do solo. Assim, a perda por infiltração ou evaporação da lâmina de água aplicada pode ser controlada e racionalizada, fornecendo água para as raízes das plantas por muito mais tempo (KABIR et al., 2017).

Nas últimas duas décadas ocorreu um aumento substancial em pesquisas voltadas para o uso de uso de polímeros hidroretentores, principalmente em regiões com limitações de recursos hídricos (NARJARY et al., 2012). Em áreas semiáridas, os processos de irrigação são particularmente caros, requerendo adaptações com vistas a baratear essa prática, ou ao menos potencializar os recursos investidos. Como resultado, o uso de hidrogéis tornou-se uma alternativa pertinente para lidar com esse problema, favorecendo as reduções de custo necessárias e a irrigação contínua para as culturas trabalhadas (MILANI et al., 2017).

A alface (Lactuca sativa L.) é umas das hortaliças mais produzidas e consumidas no Brasil (VALERIANO et al., 2018). É uma cultura bastante exigente em água, sendo extremamente sensível as condições de seca e déficit hídrico, o que se deve ao seu sistema radicular pouco profundo (KIZIL et al., 2012), dessa forma, a utilização de complementação hídrica para essa cultura se torna necessária (VALERIANO et al., 2018).

Nesse sentido, tomando como base a necessidade da utilização de técnicas que permitam a maximização do aproveitamento do uso da água na produção de alface, notadamente em regiões de carência hídrica, como o Nordeste do Brasil, objetivou-se avaliar o crescimento e produção de alface utilizando-se reposições hídricas e polímero hidroretentor.

\section{Material e Métodos}

O experimento foi conduzido de julho a agosto de 2018 em condições de ambiente protegido, no Departamento de Fitotecnia e Ciências Ambientais da Universidade Federal da Paraíba (DFCA/UFPB), no município de Areia, Paraíba, com coordenadas geográficas de 6057'48"de latitude sul e 3541'30" de longitude oeste de Greenwich, com altitude média de 618 m. O clima da região, na classificação de Köppen, é do tipo $A s^{\prime}$, (quente e úmido), com precipitação distribuída no outono-inverno, média anual de $1400 \mathrm{~mm}$.

O delineamento experimental utilizado foi em blocos com tratamentos ao acaso, com quatro repetições, em esquema fatorial $4 \times 2+2$, sendo a unidade experimental composta por duas plantas. Os tratamentos resultaram da combinação de quatro reposições hídricas (100, 80,60 e $40 \%$ da capacidade de campo), dois volumes de polímero hidroretentor diluído em água (50 e $25 \mathrm{~mL}$ ) e duas testemunhas sem o uso do polímero nas reposições hídricas de 100 e $40 \%$ da capacidade de campo. O polímero hidroretentor utilizado é caracterizado pelo fabricante como copolímero poliacrílico de potássio poliacrilamida de natureza física farelado com CTC de 532,2600 mmolc $\mathrm{dm}^{-3}$. Utilizou-se uma diluição de 5 gramas do polímero para cada litro de água, conforme a formulação recomendada pelo fabricante.

Para o plantio utilizaram-se mudas de alface cultivar Veneranda, produzidas em bandejas de polietileno de 128 células, sendo as sementes semeadas em substrato a base de composto orgânico e palha de arroz carbonizada na proporção 2:1, respectivamente. Essas mudas foram transplantadas quando apresentavam três a quatro folhas definitivas, em vasos de polietileno perfurados, com capacidade para 8 $\mathrm{dm}^{3}$. Como substrato utilizou-se um Latossolo Vermelho Amarelo coletado na camada superficial $(0-20 \mathrm{~cm})$ da área experimental do DFCA/UFPB, com textura Franco Arenosa e características físicas e químicas apresentadas na Tabela 1. 
Tabela 1. Atributos químicos e físicos do solo da área experimental na camada de $0-20 \mathrm{~cm}$. Areia, PB, 2018

\begin{tabular}{|c|c|c|c|}
\hline Atributos & Valores & Atributos & Valores \\
\hline pH em água & 5,8 & Areia $\left(\mathrm{g} \mathrm{kg}^{-1}\right)$ & 574 \\
\hline$P\left(\mathrm{mg} \mathrm{dm}^{-3}\right)$ & 13,25 & Silte $\left(\mathrm{g} \mathrm{kg}^{-1}\right)$ & 124 \\
\hline $\mathrm{K}^{+}\left(\mathrm{mg} \mathrm{dm}^{-3}\right)$ & 37,04 & Argila $\left(\mathrm{g} \mathrm{kg}^{-1}\right)$ & 302 \\
\hline $\mathrm{Ca}^{+2}\left(\mathrm{cmolc} \mathrm{dm}^{-3}\right)$ & 4,93 & Argila dispersa $\left(\mathrm{g} \mathrm{kg}^{-1}\right)$ & 77 \\
\hline $\mathrm{Mg}^{+2}\left(\mathrm{cmolc}_{\mathrm{Cm}} \mathrm{dm}^{-3}\right)$ & 0,99 & Grau de floculação $\left(\mathrm{kg} \mathrm{dm}^{-3}\right)$ & 745 \\
\hline $\mathrm{Na}^{+}\left(\mathrm{cmolc} \mathrm{dm}^{-3}\right)$ & 0,24 & Densidade do solo $\left(\mathrm{g} \mathrm{cm}^{-3}\right)$ & 1,74 \\
\hline $\mathrm{H}^{+}+\mathrm{Al}^{+3}\left(\mathrm{cmolc}_{\mathrm{c}} \mathrm{dm}^{-3}\right)$ & 3,66 & Densidade de partícula $\left(\mathrm{kg} \mathrm{dm}^{-3}\right)$ & 2,63 \\
\hline $\mathrm{Al}^{+3}\left(\mathrm{cmolc} \mathrm{dm}^{-3}\right)$ & 0,00 & Porosidade $\left(\mathrm{m}^{3} \mathrm{~m}^{-3}\right)$ & 0,34 \\
\hline $\mathrm{SB}\left(\mathrm{cmolc} \mathrm{dm}^{-3}\right)$ & 6,26 & CC 0,33 Mpa $\left(\mathrm{g} \mathrm{kg}^{-1}\right)$ & 178 \\
\hline CTC $\left(\mathrm{cmolc} \mathrm{dm}^{-3}\right)$ & 9,92 & PMP 1,50 Mpa $\left(\mathrm{g} \mathrm{kg}^{-1}\right)$ & 105 \\
\hline M.O. $\left(\mathrm{g} \mathrm{kg}^{-1}\right)$ & 14,66 & Classe Textural & Franco Arenosa \\
\hline
\end{tabular}

A adubação foi realizada conforme recomendações da cultura (CAVALCANTI, 1998), levando em consideração os resultados das análises de fertilidade. As fontes utilizadas para a adubação nitrogenada, fosfatada e potássica foram ureia, superfosfato simples e cloreto de potássio, respectivamente.

O solo foi mantido na capacidade de campo para todos os tratamentos nos cinco primeiros dias após o transplantio, após esse período as reposições hídricas foram feitas conforme cada tratamento.

A capacidade de campo no vaso (CAD) foi determinada conforme metodologia proposta por Casaroli e Van Lier (2008) e o manejo das reposições hídricas foi feito realizando-se a pesagem diária dos vasos da testemunha absoluta (100\% de reposição hídrica e sem uso de polímero) para determinação do armazenamento atual (ARMa) e cálculo da irrigação necessária conforme equação 1 .

$$
\mathrm{I}=(\mathrm{CAD}-\mathrm{ARMa}) \mathrm{xf} \text { (Equação 1) }
$$

Em que:

I - irrigação necessária, I vaso ${ }^{-1}$;

CAD - capacidade de água disponível no vaso, I vaso ${ }^{-1}$;

ARMa - armazenamento atual, I vaso ${ }^{-1}$;

f: fator de cada tratamento $(1 ; 0,8 ; 0,6$ ou 0,4 para os tratamentos de $100,80,60$ e $40 \%$ de reposição da capacidade de campo, respectivamente).

Aos 30 dias após o transplantio foram avaliadas as características de crescimento: altura de planta, diâmetro da cabeça e número de folhas. Para obtenção de altura e diâmetro da cabeça foi utilizada régua graduada em $\mathrm{cm}$. Após as avaliações de crescimento, as plantas foram colhidas e acondicionadas em sacos plásticos devidamente identificados e levadas para o Laboratório de Análise de Sementes DFCA/UFPB para determinação da massa fresca da parte aérea (parte comercial) em balança analítica; para a massa seca da parte aérea, o material foi colocado em saco de papel identificado e em estufa de circulação de ar forçado a $65^{\circ} \mathrm{C}$ até atingir massa constante e posterior determinação da massa em balança analítica.

Os resultados obtidos foram submetidos à análise de variância utilizando-se o programa estatístico SAS. Com base nas significâncias $(p \leq 0,05)$ foram testadas análise de regressão até $2^{\circ}$ grau admitindo-se $R^{2} \geq 70 \%$.

\section{Resultados e Discussão}

Observou-se efeito da lâmina de irrigação sob todas as características analisadas. Não se registrou efeito isolado significativo do hidrogel, tampouco interação entre essa fonte e as lâminas de irrigação (Tabela 2).

Verificou-se efeito quadrático da lâmina de irrigação sobre a altura média das plantas da alface (Figura 1), com incremento dessa característica com o aumento da lâmina aplicada. 
Tabela 2. Resumos das análises de variância para altura de planta (AP) diâmetro médio da cabeça (DM), número de folhas (NF), matéria fresca (MF) e matéria seca (MS) da da alface Veneranda

\begin{tabular}{lllllll}
\hline FV & GL & \multicolumn{5}{c}{ Quadrado Médio } \\
\cline { 2 - 4 } & & AP & DM & NF & MF & MS \\
\hline Lâmina (L) & 3 & $43.38^{* *}$ & $166.93^{* *}$ & $22.44^{* *}$ & $3883.74^{* *}$ & $11.09^{* *}$ \\
Hidrogel (H) & 2 & $1.71^{\mathrm{ns}}$ & $3.17^{\mathrm{ns}}$ & $0.44^{\mathrm{ns}}$ & $209.82^{\mathrm{ns}}$ & $2.30^{\mathrm{ns}}$ \\
Lx H & 4 & $2,31^{\mathrm{ns}}$ & $13.95^{\mathrm{ns}}$ & $1.43^{\mathrm{ns}}$ & $373.30^{\mathrm{ns}}$ & $1.65^{\mathrm{ns}}$ \\
Bloco & 3 & $16,96^{* *}$ & $114.37^{* *}$ & $16.34^{* *}$ & $872.75^{* *}$ & $3.47^{*}$ \\
Resíduo & 27 & 2,49 & 9,55 & 1.98 & 185.50 & 1.08 \\
\hline CV(\%) & & 10.39 & 11,20 & 10.97 & 25.65 & 27.88 \\
Média & & 15.19 & 27.59 & 12.84 & 53.08 & 3.73
\end{tabular}

$\mathrm{ns},{ }^{* *} \mathrm{e}^{*}$ : não significativo e significativo a 1 e $5 \%$ de probabilidade pelo teste $\mathrm{F}$, respectivamente; CV - Coeficiente de variação; GL - Grau de liberdade; FV - Fontes de variação

Figura 1. Altura média da alface em função de reposições hídricas. Areia, PB, 2018.

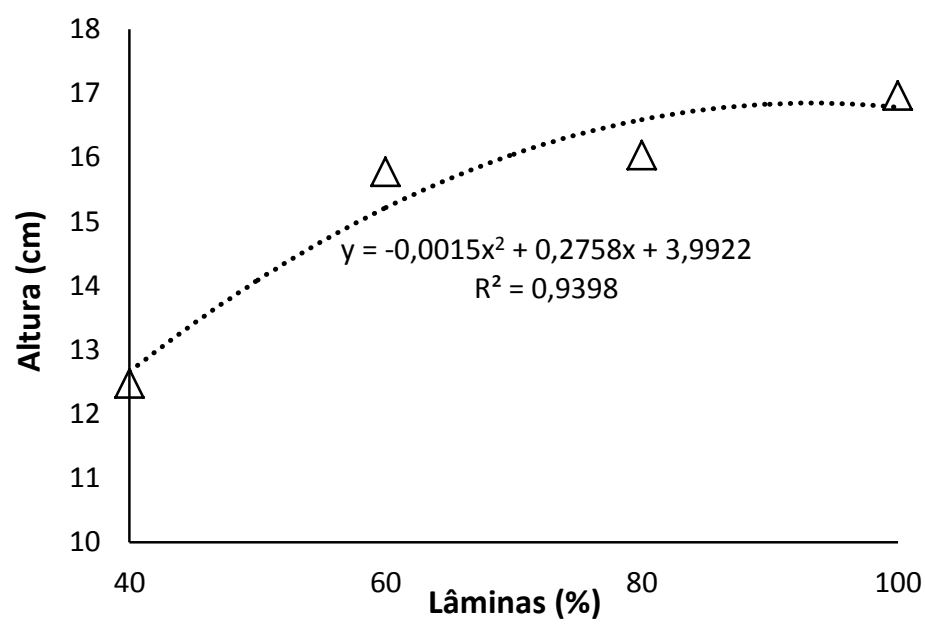

A altura média variou de 12,47 a 16,96 $\mathrm{cm}$, sendo os maiores valores obtidos com a lâmina de $100 \%$ da capacidade de campo, demonstrando assim a necessidade por parte dessa cultura de teores consideráveis de umidade no solo, para o seu pleno crescimento e desenvolvimento, o que se deve ao fato da alface ser altamente dependente da água para manter altas taxas fotossintéticas e níveis satisfatórios de crescimento (MOLINA-MONTENEGRO et al., 2011). Resultados semelhantes foram obtidos por Magalhães et al. (2015), que com a cultivar de alface Rapids, obtiveram efeito crescente da altura de plantas em função da lâmina de água disponibilizada.

Para o número médio de folhas, observou-se ganhos lineares dessa característica em função da lâmina de irrigação. A água é um componente essencial no processo de fotossíntese e desempenha um papel fundamental na transpiração, abertura estomática e crescimento e expansão das folhas, logo, o fornecimento de uma quantidade adequada de água no intervalo de desenvolvimento da alface leva a um crescimento ativo da planta, resultando na obtenção de melhores rendimentos vegetativos, entre eles, maior número de folhas (ACHARYA et al., 2013). Comportamento condizente com o observado por Valeriano et al. (2016), que para o número de folhas externas e internas da alface, obtiveram os melhores resultados com o acréscimo da lâmina utilizada. No entanto, para essa característica, assim como para as demais, não observou-se efeito isolado do hidrogel, nem interação deste com a lâmina de irrigação, resultado diferente do 
obtido por Taheri et al. (2017b), que alcançaram os maiores valores de número de folhas de alface quando esta cultura foi submetida ao uso de superabsorvente e mantida com $80 \%$ da necessidade de água requerida.

Figura 2. Número médio de folhas de alface em função de reposições hídricas. Areia, PB, 2018.

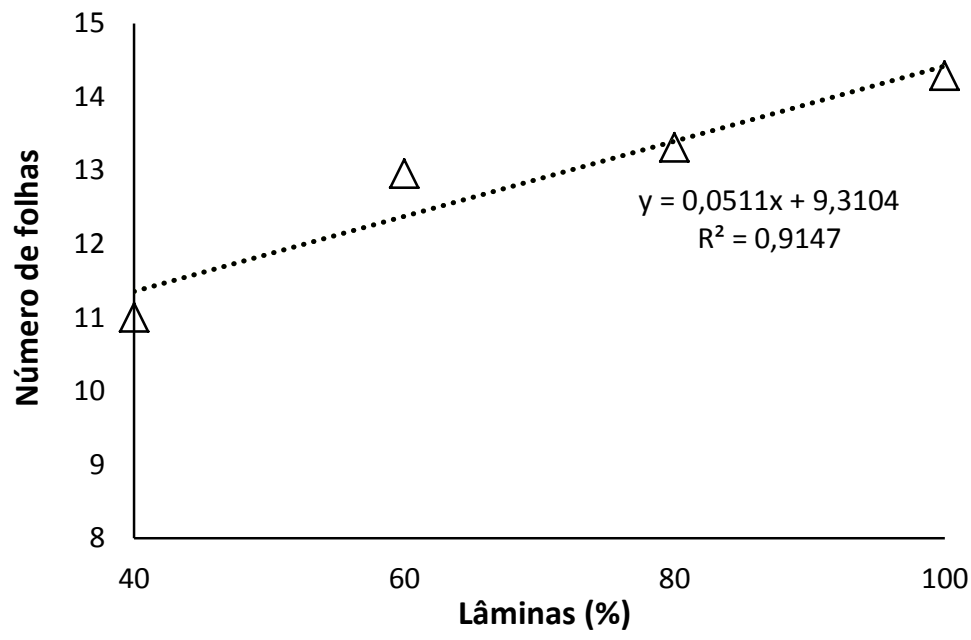

O número médio de folhas variou de 11 folhas na lâmina de $40 \%$ a 14 folhas por planta na lâmina de $100 \%$ da capacidade de campo (Figura 2). Resultados esses superiores aos reportados por Santos et al. (2015) para a alface cv. Americana sob reposição hídrica de $100 \%$ da ETc, aonde os valores dessa variável foram de 12,5 folhas por planta.

Sousa et al. (2018) para a variedade Veneranda sob irrigação convencional por aspersão em Jataí, Goiás, obtiveram médias por planta de 21,2 folhas, valores portanto superiores aos aqui observados para essa mesma variedade, todavia, deve-se considerar que os referidos autores realizaram a colheita aos 39 dias após o transplantio, enquanto no presente trabalho esse procedimento se deu aos 30 dias.

Observou-se efeito significativo da lâmina de irrigação sob o diâmetro médio das plantas de alface, com ganhos lineares $(R=91 \%)$ desse parâmetro de acordo com a lâmina aplicada (Figura 3), resultados que corroboram mais uma vez a resposta positiva da alface ao suprimento adequado de água. Magalhães et al. (2015) observaram efeito quadrático das lâminas de irrigação em relação ao diâmetro de cabeça das cultivares de alface Simpson, Rapids e Mônica, sendo a lâmina de $103,6 \%$ da ETc a que proporcionou os máximos valores para essa variável.

Figura 3. Diâmetro médio da parte aérea da alface em função de reposições hídricas. Areia, PB, 2018.

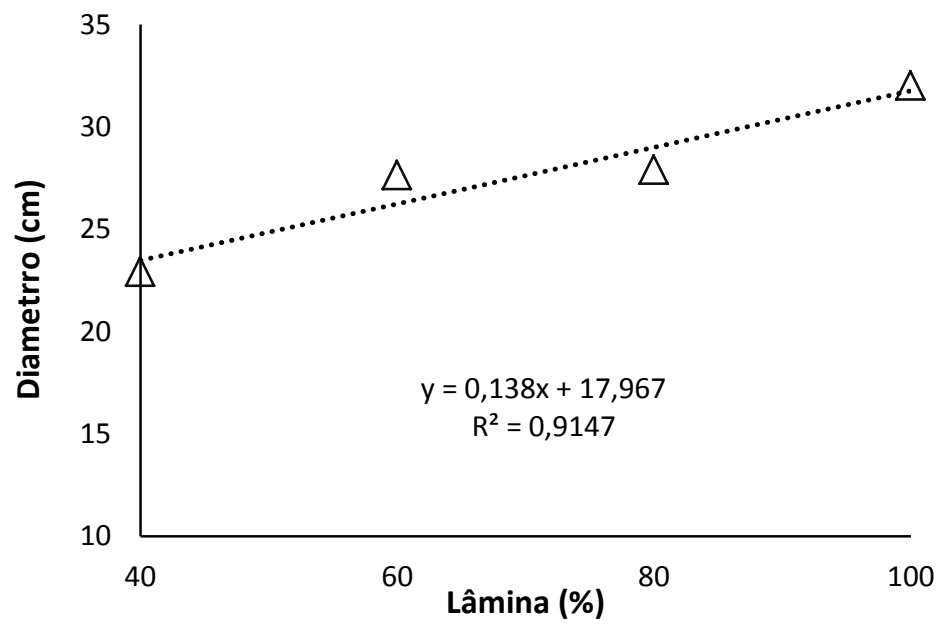


Para a lâmina de $100 \%$ da capacidade de campo, obteve-se diâmetro médio de plantas de $32 \mathrm{~cm}$, contrastando com a lâmina de $40 \%$, em que essa variável alcançou apenas $22,9 \mathrm{~cm}$. Resultado ainda assim, próximo ao reportado por Sousa et al. (2018) para a mesma cultivar aqui trabalhada, que sob irrigação convencional e aos 39 dias após o transplantio, apresentou diâmetro médio de $23,2 \mathrm{~cm}$. Evidenciando que embora não tenha influenciado significativamente, o hidrogel, colaborou positivamente para o desenvolvimento dessas plantas.

A lâmina de irrigação influenciou significativamente $(p<0,001)$ na massa da matéria fresca da parte aérea da alface, com a obtenção de ganhos lineares à medida que se aumentou a reposição hídrica ( $R=95 \%$ ) (Figura 4).

Figura 4. Massa da matéria fresca da parte aérea de alface em função de reposições hídricas. Areia, PB, 2018.

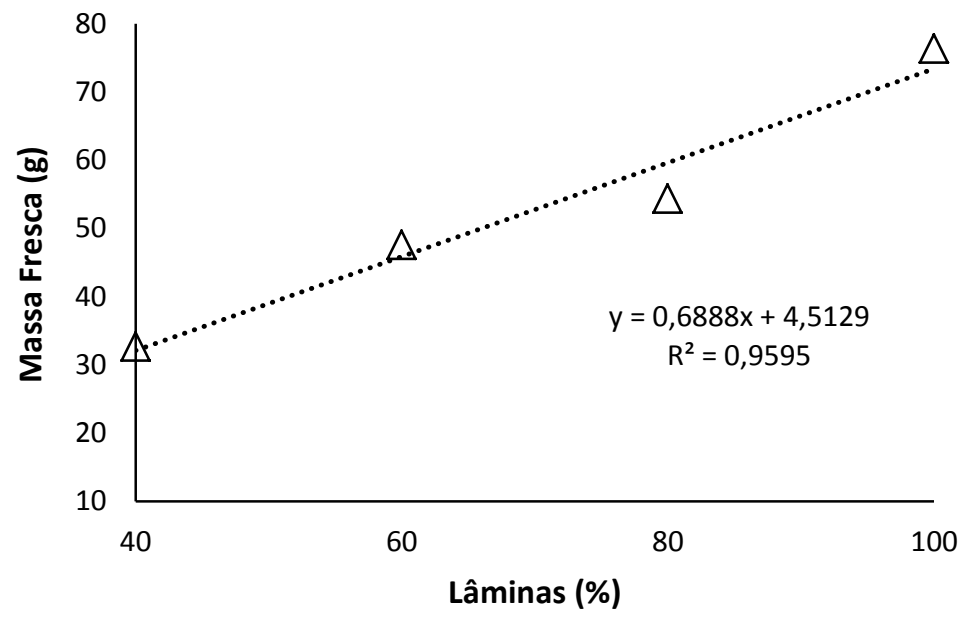

Foram obtidos $32,69 \mathrm{~g}, 47,54 \mathrm{~g}, 54,32 \mathrm{~g}$ e

$76,35 \mathrm{~g}$ por planta, que correspondem respectivamente as lâminas de $40 \%, 60 \%, 80 \%$ e $100 \%$ da capacidade de campo. Contudo, não foi significativo o uso do polímero hidroretentor, contrastando com os resultados obtidos por Taheri et al. (2017a), que ao utilizarem 8 gramas de polímero hidroretentor e uma lâmina de $60 \%$ da água requerida pela alface, tiveram um aumento na produção de matéria fresca da ordem de $41 \%$ quando comparado com o tratamento controle. No entanto, os resultados obtidos foram satisfatórios, visto que os valores da massa da matéria fresca da parte aérea aqui obtidos, foram em grande parte superiores aos relatados por Ferreira et al. (2015) que para a variedade Veneranda cultivada em ambiente protegido, obtiveram valores médios para essa variável de 59,06 gramas.

A redução na oferta de água leva ao déficit hídrico, que para essa cultura é responsável por uma menor produção de folhas e, consequentemente, menor massa fresca da parte área (PUTTI et al., 2015). Em condições de suprimento adequado de água, como observado nesse trabalho para as maiores lâminas de irrigação, principalmente a de $100 \%$ da capacidade de campo, a alface tende a demonstrar respostas positivas para as suas características de crescimento e acúmulo de biomassa (MAGALHÃES et al., 2015). Situação comprovada tanto com os resultados aqui obtidos, como por outros trabalhos da literatura científica, como por exemplo, Araújo et al. (2010) que comprovaram em pesquisa com a cultura da alface, que esta responde a elevadas lâminas de irrigação, resultando em um aumento da massa de matéria fresca total por planta.

Observou-se efeito significativo da lâmina de irrigação sob a massa da matéria seca da parte aérea da alface. Contudo, não foi significativo o uso do polímero hidroretentor, resultado semelhante ao observado por Oliveira et al. (2014) para a alface "Mimosa Roxa" que ao ser submetida a cinco níveis de hidrogel aplicados no solo $\left(0,50,100,150\right.$ e $\left.200 \mathrm{~g} \mathrm{~m}^{-2}\right)$ não sofreu influência significativa deste na maior parte das variáveis analisadas, entre elas a massa seca da parte aérea.

O valor médio da massa seca da parte aérea da alface, apresentou um comportamento semelhante ao da massa fresca (Figura 5), com 
ganhos lineares $(R=98 \%)$ de acordo com 0 aumento da lâmina de irrigação, no entanto, essa característica foi menos afetada que a massa fresca, o que se deve ao fato de que a diminuição da oferta de água ter um maior efeito no peso fresco do que no peso seco dessa cultura (BOZKURT; MANSUROĞLU, 2011). Os valores desse parâmetro variaram de 2,62 a 4,94 gramas, com os melhores resultados sendo obtidos na lâmina de $100 \%$ da capacidade de campo. Cassimiro et al. (2019) utilizando uma lâmina de $100 \%$ da ETo obtiveram valores de massa seca da parte aérea da alface superiores a esse estudo, com médias superiores a 12 gramas por planta.

Figura 5. Massa da matéria seca da parte aérea da alface em função de reposições hídricas Areia, PB, 2018.

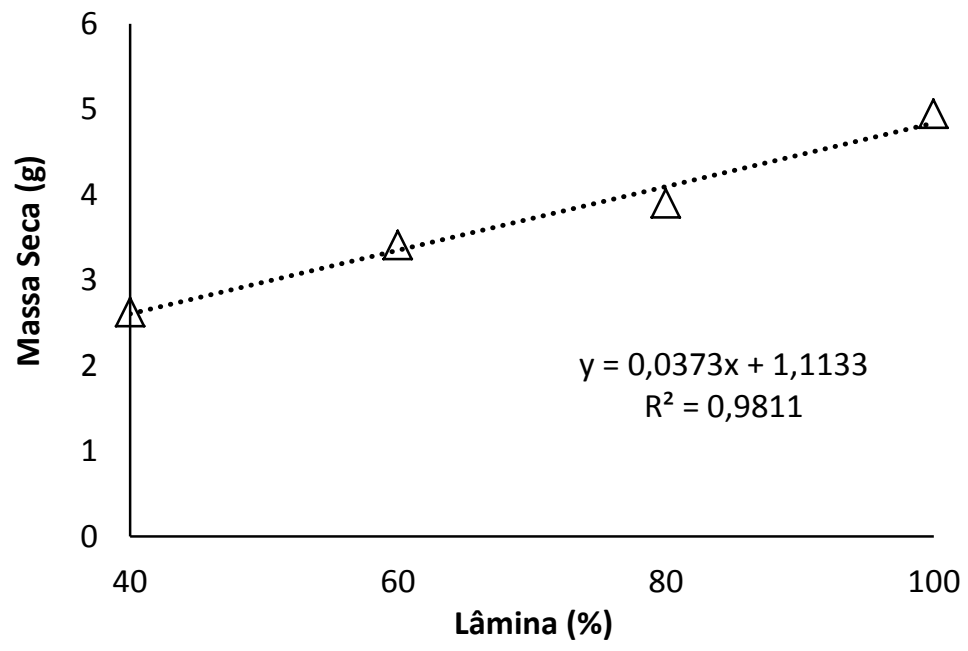

A não obtenção de resultados significativos para a utilização do hidrogel neste experimento pode estar atrelada às características do solo utilizado, que apresenta uma textura franco arenosa, o que associada à quantidade de polímero aplicada, não propiciou uma ação eficiente deste produto. Segundo Santos et al. (2015), a alface cultivada em solo argiloso apresenta melhor produção em baixas doses de hidrogel se comparada com a alface produzida em solo arenoso, sendo recomendada para esse tipo de solo o uso de doses maiores. Ademais, o tipo de reposição hídrica utilizada, baseada no fornecimento da água necessária para a planta diretamente na base da mesma, resultou em perda mínima de água até para as menores lâminas de reposição, o que pode ter influenciado também na ação do hidrogel.

\section{Conclusões}

O uso de polímero hidroretentor nas dosagens aplicadas não influenciou significativamente em nenhuma das características de produção avaliadas. A alface apresenta maior crescimento e produtividade com a lâmina de água de $100 \%$ da capacidade de campo.
Referências

ACHARYA, S. K.; SHUKLA, Y. R.; KHATIK, P. C. Effect of water regime on growth and yield of lettuce (Lactuca sativa L.). An International Quarterly Journal of Life Sciences, v.8, n.1, p.201-206, 2013.

ARAÚJO, W. F; SOUZA, K. T. S; VIANA, T. V; AZEVEDO, B. M; OLIVEIR, G. A. Rendimento e eficiência do uso da água pela alface em função da lâmina de irrigação. Caatinga, v.23, n.4, p.115120, 2010.

BOZKURT, S.; BOZKURT, G. S. The effects of drip line depths and irrigation levels on yield, quality and water use characteristics of lettuce under greenhouse condition. African Journal of Biotechnology, v.10, n.17, p.3370-3379, 2011. DOI: https://doi.org/10.5897/AJB10.1899

CASAROLI, D.; VAN LIER, J. Criteria for pot capacity determination. Revista Brasileira de Ciência do Solo, v.32, n.1, p.59-66, 2008. DOI: http://dx.doi.org/10.1590/S0100$\underline{06832008000100007}$ 
CASSIMIRO, C. A. L.; OLIVEIRA, F. S.; SILVA, E. A.; FEITOSA, S. S.; SIQUEIRA, E. C.; SILVA, M. G. Lâminas de água múltiplas via sistema de irrigação subsuperficial no cultivo de alface do grupo crespa. Brazilian Journal of Environmental Management, v.13, n.1, p.08-12, 2019. DOI: https://doi.org/10.18378/rbga.v13i1.6132

CAVALCANTI, F.J.A. Recomendações de adubação para o estado de Pernambuco $\left(2^{a}\right.$ aproximação), CAVALCANTI, F.J.A., coord., 2.ed. Recife, Instituto Agronômico de Pernambuco, 1998. 198p

FERREIRA, L. G.; RIZENTAL, M.; MOLIN, Í. A. D.; MONDIN, M.; NESSI JUNIOR, P. Produtividade de cultivares de alface em dois ambientes em Várzea Grande-MT. Connection Line, n.13, p.24-35, 2015. DOI: http://dx.doi.org/10.18312\%2F19807341.n13.2015.242

GUILHERME, M. R.; AOUADA, F. A.; FAJARDO, A. R.; MARTINS, A. F.; PAULINO, A. T.; DAVI, M. F. et al. Superabsorbent hydrogels based on polysaccharides for application in agriculture as soil conditioner and nutrient carrier: $A$ review. European Polymer Journal, v.72, p.365385, 2015.2 DOI: https://doi.org/10.1016/j.eurpolymj.2015.04.017

KABIR, M. H.; AHMED, K.; FURUKAWA, H. A low cost sensor based agriculture monitoring system using polymeric hydrogel. Journal of The Electrochemical Society, v.164, n.5, p.B3107B3112, 2017.2 DOI: https://doi.org/10.1149/2.0171705jes

KIZIL, Ü.; GENC, L.; INALPULAT, M.; ŞAPOLYO, D.; MIRIK, M. Lettuce (Lactuca sativa L.) yield prediction under water stress using artificial neural network (ANN) model and vegetation indices. Žemdirbystè = Agriculture, v.99, n.4, p.409-418, 2012.

MAGALHÃES, F. F; CUNHA, F. F; GODOY, A.R; SOUZA, E. J; SILVA, T. R. Produção de cultivares de alface tipo crespa sob diferentes lâminas de irrigação. Water Resources and Irrigation Management, v.4, n.1-3, p.41-50, 2015. DOI: http://dx.doi.org/10.19149/2316-

6886/wrim.v4n1-3p41-50

MILANI, P.; FRANÇA, D.; BALIEIRO, A. G.; FAEZ, R. Polymers and its applications in agriculture. Polímeros, v.27, n.3, p.256-266, 2017. DOI: http://dx.doi.org/10.1590/01041428.09316

MOLINA-MONTENEGRO, M. A.; ZURITA-SILVA, A.; OSES, R. Effect of water availability on physiological performance and lettuce crop yield (Lactuca sativa). Ciencia e Investigación Agraria, v.38, n.1, p. 65-74, 2011. DOI: http://dx.doi.org/10.467/s071816202011000100006.

NARJARY, B.; AGGARWAL, P.; SINGH, A.; CHAKRABORTY, D.; SINGH, R. Water availability in different soils in relation to hydrogel application. Geoderma, v.187, p.94-101, 2012. DOI:

https://doi.org/10.1016/j.geoderma.2012.03.002

OLIVEIRA, G.Q.; BISCARO, G.A.; JUNG, L.H.; ARAÚJO, É.O.; VIEIRA FILHO, P.S. Fertirrigação nitrogenada e níveis de hidrogel para a cultura da alface irrigada por gotejamento. Engenharia na Agricultura, v.22, n.5, p.456-465, 2014. DOI: https://doi.org/10.13083/reveng.v22i5.508

PUTTI, F. F.; GABRIEL FILHO, L. R. A.; KLAR, A. E.; SILVA JUNIOR, J. F.; CREMASCO, C. P.; LUDWIG, R. Response of lettuce crop to magnetically treated irrigation water and different irrigation depths. African Journal of Agricultural Research, v.10, n.22, p.2300-2308, 2015. DOI: https://doi.org/10.5897/AJAR2015.9616

SANTOS, H.T.D.; CARVALHO, D.F.D.; SOUZA, C.F.; $\mathrm{MEDICl}$, L.O. Lettuce growing under automated irrigation and hydrogel application. Engenharia Agrícola, v.35, n.5, p.852-862, 2015. DOI: http://dx.doi.org/10.1590/1809-4430-

Eng.Agric.v35n5p852-862/2015

SANTOS, M. A. L.; SANTOS, D. P.; MENEZES, S. M.; LIMA, D. F.; VIEIRA, J. P. S. Produção da cultura da alface (Lactuta sativa $\mathrm{L}$ ) em função das lâminas de irrigação e tipos de adubos. Revista Ciência Agrícola, v. 13, n. 1, p. 33-40, 2015. DOI: http://dx.doi.org/10.28998/rca.v13i1.1652

SOUSA, V. S.; MOTA, J. H.; CARNEIRO, L. F.; YURI, J. E.; RESENDE, G. M. Desempenho de alfaces do grupo solta crespa cultivadas no verão em JataíGO. Cultura Agronômica: Revista de Ciências Agronômicas, v.27, n.3, p.288-296, 2018. 
TAHERI, H.; MOHAMMADI, A.S.; ANSARI, N.A. Effects of superabsorbent polymer on the number and leaf area of lettuce under drought stress. Journal of Water Science \& Engineering, v.7, n.15, p.71-80, 2017b.

TAHERI, H.; MOHAMMADI, A.S.; ANSARI, N.A. Effect of Superabsorbent Polymer on Yield of Lettuce. Researcher, v.9, n.6, p.63-66, 2017a. DOI: https://doi.org/10.7537/marsrsj090617.10

VALERIANO, T.T.B.; SANTANA, M.J.; JESUS, M.V.; LEITE, S.U.D. Manejo de irrigação para a alface americana cultivada em ambiente protegido. Nativa: Pesquisas Agrárias e Ambientais, v.6, n.2, p.118-123, 2018. DOI: http://dx.doi.org/10.31413/nativa.v6i2.5024

VALERIANO, T.T.B.; SANTANA, M.J.; OLIVEIRA, A.F; MACHADO, L.J. Alface americana cultivada em ambiente protegido submetida a doses de potássio e lâminas de irrigação. Irriga, v.21, n.3, p.620-630, 2016.2 DOI: https://doi.org/10.15809/irriga.2016v21n3p620$\underline{630}$ 